\section{BACK TO THE NORMALCY; IS IT POSSIBLE AFTER THE LATEST CORONAVIRUS DISEASE-COVID-19 ATTACK?}

While writing these sentences I feel a sharp pain in my throat and even sharper is disturbing my heart- the fear of severe contagious disease. At the same time stressful radio news warn me how the infection could be dangerous: informing about the number of newly diagnosed, those who died yesterday, and those that are on ventilators.

On December 29, 2019 the first four cases of "pneumonia of unknown etiology" were identified by local hospitals, all linked to the Huanan (Southern China) Seafood Whole-Sale Market. Since then an increasing number of cases of novel coronavirus pneumonia have been identified in Wuhan, a large city of 11 million people in Central China [1]. Pneumonia of unknown etiology is defined as an illness without identified causative pathogen that fulfills following criteria: fever $\left(\geq 38^{\circ} \mathrm{C}\right)$, radiographic evidence of pneumonia, low or normal white blood cell count or low lymphocyte count, and no symptomatic improvement after antimicrobial treatment for 3 to 5 days following the standard clinical guidelines. Severe acute respiratory syndrome coronavirus 2 (SARS-CoV-2), the virus that causes coronavirus disease 2019 (COVID-19), was quickly identified. On January 31, 2020, the WHO declared coronavirus a global health emergency. It abruptly generated a worldwide pandemic $[1,2]$. The experience from Severe Acute Respiratory Syndrome (SARS) and the Middle East respiratory syndrome (MERS) case definitions as recommended by the WHO in 2003 and 2012 respectively were applied, but the new coronavirus unexpectedly showed its sneaky nature. It was different and it produced confusion and uncertainty among members of "The expert community". Whoever gave opinions and prognoses was deeply wrong.

Coronavirus outbreak forced us to interrupt our normal activities and to postpone our annual meetings and congresses. It seemed that it disrupted all activities on the planet except the bare essentials. The burden of the severe cases of SARS-CoV-2 overwhelmed health care capacities even in the developed western countries. Besides infectologists, pulmonologists, and anesthesiologists, many different specialists and subspecialists were engaged as first - line practitioners in the triage of suspected patients and even in the treatment of severely ill patients in need of vital support. The younger ones have been forced to work for months in so-called COVID - hospitals, changing their focus of clinical practice and scientific interest towards practical essentials in the treatment of COVID-19 infected patients. Virus gave us a lecture on how arrogant but helpless and minor we are at the same time. We are not permitted to go outside without masks, to shake hands with colleagues, nor to hug friends or family members-restrictions advised to patients with immunodeficiency. Just as COVID-19 causes physiological dysfunction in patients, so too, it caused systemic

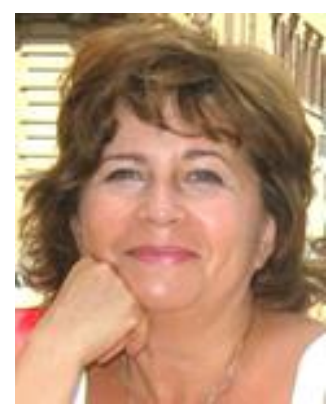

Correspondence to: Ljiljana Šaranac, M.D., Ph.D.

Faculty of Medicine, Braće Tasković 81 Blvd., Niš, Serbia

Phone: +381628242161

E-mail: endoljilja@yahoo.com

Received July $27^{\text {th }}, 2020$ 
dysfunction in households, institutions, cities, and nations [2, 3]. In every evil, some benefit could lie: air pollution decreased, rivers became cleaner, terrorism stopped and wars halted. The flora and fauna are relieved.

Coronaviruses have been well known for decades as commonest pathogens, besides rhinoviruses and Respiratory Syncytial Virus (RSV) responsible for the upper respiratory tract infections in children and adults- the common cold (coryza) when patients and parents were advised that there is no need for specific curative treatment. The illness was mild and self-limiting. What changed this coronavirus from harmless to virus responsible for the high mortality rate among affected individuals? The virus obviously transformed its nature, but that is us who also changed. Our immune system is overreacting or stay in ignorant condition once the virus entered the body. Some individuals, mainly young people and children, in good condition as sportists, did not show any sign of disease, while others were producing strong infammation and even ,cytokine storm“.

Virus taught us what are fundamental human needs, besides essentials for life: food, water, shelter, sleep, physical and emotional connections and need for novelties. Novelty creates the opportunity to learn and the potential to fail. Without novelties, motivation wanes and a healthy sense of well-being is lost. Furthermore people need a place to gain and share knowledge, empowering to learn from others and better understand the world. Contentedness increases selfesteem, a sense of security, a sense of belonging... The virus jeopardized all above mentioned human needs.

What are the facts and controversies about the current pandemic?

In order to invade host cells SARS-CoV-2 (the virus responsible for the COVID-19 pandemic) and SARS-CoV-1 (responsible for the SARS epidemic in 2002) need to bind cell surface receptor angiotenzin-converting enzyme 2 (ACE2). They are expressed mainly in lungs, heart and kidneys. These receptors are sparse in children, explaining why children are less affected. This entry into host cells requires besides ACE2, the cleavage of S-spike protein of the corona virus surface by transmembrane protease serine 2 (TMPRSS2), which thus represents a critical host cell factor for the invasion and spread of the virus. The protease is upregulated by androgens, the fact that clarifies why male subjects are more frequently affected. Thus, it is also expected that hypertensive patients treated with the ACE inhibitors could have facilitated viral invasion $[4,5]$.

Captopril has recently been questioned for patients with diabetes in COVID-19 settings. Although ACE inhibitors and angiotensin receptor blockers (ARBs) are generally considered to have similar adverse event profiles, evaluation of postmarketing adverse events may shed light on minute differences that could have important clinical impacts during actual pandemic. Captopril appears to be associated with a higher rate of pulmonary adverse reactions in patients with diabetes than other ACE inhibitors or ARBs and therefore may not be the best choice for patients with diabetes and COVID-19, a new study suggests [5].

What was not curiosity for me as an endocrinologist is the new study's result that dexamethasone reduced mortality by one-third in ventilated patients and by one fifth in other patients receiving oxygen only.The study stoped because the survival benefit for a lifethreatening disease was obvious. Continuing the study as originally designed is unethical - those randomized to receive "usual care" would be deprived of a potentially life-saving treatment [6,7]. Aside from those patients in whom corticosteroids are contraindicated, it is hard to imagine to not offer dexhametasone nowadays to a person 
with COVID-19 who requires supplemental oxygen or ventilator support [6]. It is well known that adequate adrenocortical function is essential for survival in critical illness. Most critically ill patients display elevated plasma cortisol concentrations, which reflect activation of the hypothalamic-pituitary-adrenal axis and is considered to be a homeostatic adaptation. However, many critically ill patients have "relative" or "functional" adrenal insufficiency, which is characterized by an inadequate production of cortisol in relation to an increased demand during periods of severe stress. Not so recently, the term "critical illness-related corticosteroid insufficiency" (CIRCI) was introduced. CIRCI occurs as a result of a decrease in adrenal steroid production or tissue resistance to glucocorticoids [8]. Thus, It is reasonable to apply dexamethasone or methyprednisolone in severe COVID-19 or any other severe pneumonia as our pulmonologists have actually been doing for years.

There is another intriguing involvement of endocrine system with potential to produce long term consequences on growth and development in children, as well as on the well-being, healthy aging or even survival in adults.It is the potential of affecting the pituitary gland. Namely, hypocortisolism in survivors of SARS was reported in 2005. The authors speculated that the coronavirus infection could have caused a reversible hypophysitis [4,9]. Reversible or permanent - the time will show. So we must be prepared for a potential long-term endocrine impact of the disease that will reveal its real nature in the future.

Is a coagulation cascade crucial for the development of clinical presentation from the very beginning or its activation means final event? We consulted prof. Jovan Antović, $\mathrm{PhD}$, an expert and Research Group Leader from Clinical Chemistry - Coagulation, Dept. Molecular Medicine Surgery and Medical head Coagulation Clinical Chemistry, Karolinska University Laboratory, and a member of our Editorial board to clarify the coagulation cascade activation in SARS-CoV-2. He opened many questions and offered solutions of critical importance for avoiding the fatal outcome. To find more on this topic read the Opinion Article that professor Antovic kindly accepted to write for Facta. He presented the first experiences in investigation and treatment of such patients in his institution [10].

Under pandemic circumstances and curfew, telemedicine finds its place in follow-up and surveillance of the older population with chronic diseases. Our Italian colleague Susanne Buechner and her team from the Department of Neurology/Stroke Unit, Bolzano Hospital, Bolzano/Bozen Italy shared their experience in applying telemedicine as an effective tool that replaces periodic medical examinations in patients suffering from Parkinson's disease during COVID-19 pandemic when non urgent medical visits were impossible [11].

In the middle of this crisis we should behave like professionals and focus our energy on contribution to widen knowledge and share experiences; how to boost our immune system to resist the fatal infection or how to halt a "storm we have never seen before", a cytokine storm adjacent by deleterious disseminated intravascular coagulation.Endocrine system as critical for survival should take a big part in investigation of hormonal differences between survivors and non-survivors during this pandemic.

I find appropriate to finish this Editorial by citing Juval Noa Harari, who said: "Forced physical distance and separation will create a new closeness and intimacy between people. The importance of the health system and health workers will be re-appreciated.The greatest danger is not the virus itself but our own inner demons, our hatred, greed and ignorance". 


\section{References}

1. Li Q, Guan X, Wu P, Wang X, Zhou L, Tong Y, et al. Early transmission dynamics in Wuhan, China, of novel Corona virus-infected pneumonia. N Eng J Med 2020; 382(13):1200-1207. doi: 10.1056/NEJMoa2001316

2. Berlin DA, Gulick RM, Martinez FJ. Severe Covid-19. N Engl J Med 2020. doi: 10.1056/NEJMcp2009575

3. De Lima Thomas J. Pandemic as teacher - forcing clinicians to inhabit the expirience of serious illness. N Eng J Med 2020; 383:306-307. doi: 10.1056/NEJMp2015024

4. Cianfrani S. Pediatric Endocrinology in the time of the Covid-19 Pandemic. Horm Res Pediatr 2019; 92:345-346. doi: 10.1159/000507703

5. Stafford EG, Riviere JE, Xu X, Kawakami J, Wyckoff GJ, Jaberi-Douraki M. Pharmacovigilance in patients with diabetes: A data-driven analysis identifying specific RAS antagonists with adverse pulmonary safety profiles that have implications for COVID-19 morbidity and mortality. J Am Pharm Assoc 2020. doi: 10.1016/j.japh.2020.05.018

6. Sax PE. Dexamethasone Improves survival in COVID-19 - Why This Should Be Practice Changing Even Before the Paper is Published. [internet] NEJM Journal Watch June 21st, 2020HIV and ID Observations Blogs. [cited $2020 \mathrm{Jul}$ 26] Available from: https://blogs.jwatch.org/hiv-id-observations/index.php/ dexamethasone-improves-survival-in-covid-19-why-this-should-be-practicechanging-even-before-the-paper-is-published/2020/06/21/

7. The RECOVERY Collaborative Group. Dexamethasone in hospitalized patients with Covid-19 — preliminary report. N Engl J Med 2020. doi: 10.1056/ NEJMoa2021436

8. Levy-Shraga Y, Pinhas-Hamiel O. Critical Illness-Related Corticosteroid Insufficiency in children. Horm Res Paediatr 2013; 80:309-317. doi: 10.1159/ 000354759

9. Leow MK, Kwek DS, Ng AW, Ong K, Kaw GJ, Lee LS. Hypocortisolism in survivors ofsevere acute respiratory syndrome (SARS). Clin Endocrinol (Oxf). 2005; 63(2):197-202. doi: 10.1111/j.1365-2265.2005.02325.x

10. Antovic JP. Hemostatic abnormalities in Covid-19: underlying mechanisms and clues to treatment: do we really see a "storm" never seen before? FU Med Biol 2020; 22(1):1-6. doi: 10.22190/FUMB200620002A

11. Buechner S, La Licata A, Seppi D, Teatini F. Telemedicine during the COVID-19 pandemic: experience from an Italian outpatient clinic for Movement Disorders. FU Med Biol 2020; 22(1):21-23. doi: 10.22190/ FUMB200518004B.

Editor-in-Chief

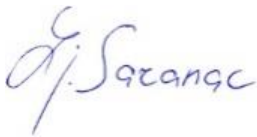

Ljiljana Šaranac 